\title{
Can readmission rates be used as an outcome indicator?
}

\author{
Ruairidh Milne, Aileen Clarke
}

There has been interest in the use of readmission rates as an outcome indicator in hospitals since at least 1965, when in their pioneering study Acheson and Barr suggested that the readmission rate might serve "as an index of the quality of medical care." This idea has lately regained ground, ${ }^{2}$ and readmission rates have been described as "one of the few potential measures available from routine statistics for assessing outcome." " This paper attempts to clarify how far readmission rates can be useful as an indicator of outcome.

\section{Outcome indicators}

Health service indicators (previously called performance indicators) are numbers derived from routinely collected data that are promoted by the Department of Health as a way of comparing the work of health care providers. ${ }^{4}$ One of their limitations is that they relate more to process than to outcome ${ }^{56}$ that is, they tell us little about what is achieved for patients and their health. Outcome indicators, by contrast, show how far a service has achieved its objectives.

Current interest in outcome indicators owes much to recent pressure from government ${ }^{8-10}$ but has also been fuelled by the frustration of clinicians with process oriented health service indicators, and interest will surely grow with the division between providers of hospital care and purchasers. " Outcome indicators will be needed by purchasers if they are to choose between hospitals on the basis of quality as well as cost, ${ }^{10}$ and providers will want similar information so that they know about the effectiveness and efficiency of their services. As the government is implementing its proposals "at an amazing speed"12 the need to develop outcome indicators is urgent.

\section{Pros and cons of readmission rates}

Hospital information systems were not designed to measure outcomes and so there are few routinely available outcome indicators. Death rates in hospital have been proposed, ${ }^{13}$ but their drawbacks are immense, ${ }^{14}$ and the suggested use of readmission rates ${ }^{1-3}$ is therefore attractive. Readmissions cause wide concern, ${ }^{15} 16$ they are more common than deaths in hospital, and they occur in all inpatient specialties. Furthermore, identifying readmissions in England and Wales is now fairly easy with the hospital information systems based on Körner data introduced in 1987. ${ }^{17}$

Before readmission rates are used as an outcome indicator, however, their limitations must be assessed. Firstly, they share with other indicators several limitations of method including errors in hospital data, ${ }^{18} 19$ random variation due to small numbers, ${ }^{18221}$ variation among hospitals in case mix and severity, ${ }^{1322}$ and problems in defining the denominator. ${ }^{23}$ These will not be discussed further, although they should always be considered when interpreting indicators. Secondly, it is important to be clear that readmissions are not in themselves measures of outcome, in the sense that avoiding readmission is not a direct objective of hospital care: some readmissions are planned, and some unplanned readmissions are unavoidable. What is a direct, though limited, objective of hospital care, and therefore a true measure of outcome, is to avoid those adverse outcomes that lead to readmission. This distinction is crucial, as the type of readmissions to be avoided are the result of two events: an avoidable adverse outcome of the first admission (bad) and the decision to readmit a patient in need of care (good). A rise in the readmission rate might, therefore, be due either to more adverse outcomes after a first admission or to a lower threshold for readmission. This means that variations in readmission rate with time or place cannot be assumed to be associated with equivalent variations in patient outcome.

The problem is that the avoidable adverse outcomes of interest cannot be measured with routine hospital statistics whereas now readmissions can. As an outcome measure, then, readmissions are being used as a proxy for avoidable adverse outcomes. The use of proxies is familiar in screening, in which a simple test is used as a proxy for a more complex diagnostic test. Developing the analogy with screening ${ }^{24}$ allows the validity of readmissions as a proxy to be explored, using a $2 \times 2$ table (table I). ${ }^{25}$

\section{Validity of readmissions as a proxy}

\section{Improving the working definition of readmissions}

The working definition of readmission - that is, that used to calculate readmission rates - may be refined in various ways to improve its validity as a proxy. Specificity $(d /(b+d))$ (table $I)$ is increased by reducing the number of false positives (b) - that is, excluding patients without an avoidable adverse outcome. For instance, a large Canadian study of surgical readmissions and outcomes was restricted to patients who had had cholecystectomy or hysterectomy for nonmalignant conditions or appendicectomy and who were readmitted within 28 days. ${ }^{26}$ The sensitivity of readmissions as a proxy $(a /(a+c))$ is increased by reducing the number of false negatives (c) - that is, counting as many patients as possible with an avoidable adverse outcome. In practice this means "catching" as many readmissions as possible by using information systems that correctly link patients and cover several hospitals.

\section{Interpreting readmission rates}

Once appropriate refinements have been made to the working definition of readmission the crucial question is: Can the readmission rates of two districts (or hospitals or consultants) be compared and inferences drawn about their relative outcomes? To answer this question two aspects of the validity of readmission as a proxy need to be known: (a) What proportion of readmissions represent an avoidable adverse outcome (the avoidability proportion) $(a /(a+b)$ : the positive predictive value in screening tests)? and $(b)$ What proportion of patients with an avoidable adverse outcome are readmitted (the readmission proportion) $(\mathrm{a} /(\mathrm{a}+\mathrm{c})$ : sensitivity in screening tests)?

\section{Avoidability proportion (positive predictive value)}

Of these two aspects of validity, only avoidability has been discussed in published reports (see accompanying paper $\left.^{27}\right)$. In principle avoidability is easy to measure: 


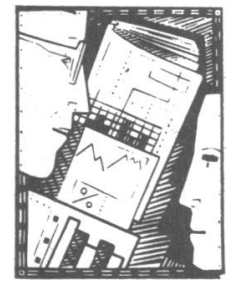

TABLE I - Validity of readmissions as a proxy for avoidable adverse outcome

\begin{tabular}{|c|c|c|c|}
\hline \multicolumn{4}{|c|}{$\begin{array}{l}\text { Occurrence of avoidable } \\
\text { adverse outcome }\end{array}$} \\
\hline & Yes & No & Total \\
\hline \multicolumn{4}{|c|}{ Readmission: } \\
\hline Yes & $\mathrm{a}$ & b & $a+b$ \\
\hline No & c & d & $c+d$ \\
\hline Total & $a+c$ & $b+d$ & $b+c$ \\
\hline
\end{tabular}

Total $a+c \quad b+d \quad a+b+c+d$ patients readmitted to hospital are identified, their case notes are reviewed, and the number of readmissions that would have been avoided by some improvement in the quality of care is assessed. In practice, difficulties abound, particularly in defining readmission and in defining and assessing avoidability. Without a special study, ${ }^{27}$ therefore, it is impossible to say how many readmissions in a named hospital are due to avoidable adverse outcomes.

\section{Readmission proportion (sensitivity)}

The second aspect of validity that must be considered relates to cell " $c$ " in table I: how many patients with avoidable adverse outcomes are not counted as readmissions, not because of cross boundary flows but because they are not readmitted to hospital anywhere? This issue of false negatives has been ignored in published reports, presumably because it is impossible to measure from hospital data. Yet we know that false negatives must exist. The numerous published reports on variations in hospital admissions make it clear that for most diseases admission rates obtained from hospital admission rates are a poor guide to the incidence of diseases in the community. ${ }^{1828}$ Other factors affect admission to hospital including patient behaviour, the extent of lay care, primary care services, the clinical judgment of hospital doctors, the availability of beds, and so on. For a given level of morbidity after discharge we can therefore be confident that the readmission proportion will vary among different hospitals.

\section{Making comparisons and assumptions}

Readmission rates may be used to compare hospitals' outcome rates only if we have two extra pieces of information: the proportion of readmissions that are avoidable (the avoidability proportion) and the proportion of patients with adverse outcomes who are readmitted (the readmission proportion). Unfortunately, these can only be estimated with local ad hoc research and cannot be derived from routinely collected data.

The following hypothetical example illustrates the importance of knowing the avoidability and readmission proportions before comparing outcome between two hospitals. Table II shows the position for hospitals $A$ and B, both with 2000 discharges in one month. Hospital B, perhaps with less pressure on beds, had fewer patients with adverse outcomes and yet readmitted more of them. It thus had the higher readmission rate $(6.0 \% v 5.0 \%)$ despite the lower rate of avoidable adverse outcome rate $(2.5 \% v 4.8 \%)$. It had the worse health service indicator but would have been in the unenviable position of being unable even to investigate the alleged problem.

\section{Conclusions}

Certainly, many readmissions represent a failure of the best care, ${ }^{1516}$ and unplanned readmission might usefully form the focus of medical audit. ${ }^{15}$ As readmission rates are now measurable there is growing interest in their use as an outcome indicator.

Ideally, outcome indicators should be chosen that measure genuine service objectives. ${ }^{27}$ When that is not possible and proxy indicators are used it is crucial that the issue of validity is recognised; otherwise "perverse incentives" will be generated. (As a readmission rate can be altered by changing the threshold for readmission its use as an outcome indicator may encourage clinicians not to readmit patients who need to be in
TABLE II-Hypothetical comparison of adverse outcomes in two hospitals

\begin{tabular}{|c|c|c|c|c|c|}
\hline & \multicolumn{2}{|c|}{$\begin{array}{l}\text { Occurrence of avoidable } \\
\text { adverse outcome }\end{array}$} & \multirow[b]{2}{*}{ Total } & \multirow{2}{*}{$\begin{array}{l}\text { Readmission } \\
\text { rate }(\%)\end{array}$} & \multirow{2}{*}{$\begin{array}{c}\text { Avoidable } \\
\text { adverse } \\
\text { outcome } \\
\text { rate }(\%)\end{array}$} \\
\hline & Yes & No & & & \\
\hline \multicolumn{6}{|c|}{ Hospital A } \\
\hline $\begin{array}{r}\text { Readn } \\
\text { Yes }\end{array}$ & $\begin{array}{l}\text { ission: } \\
50\end{array}$ & & 100 & & \\
\hline No & 30 & 1870 & 1900 & \multicolumn{2}{|c|}{$5 \cdot 0(100 / 2000) 4 \cdot 0(80 / 2000)$} \\
\hline Total & 80 & 1920 & 2000 & & \\
\hline \multicolumn{6}{|c|}{ Hospital B } \\
\hline $\begin{array}{l}\text { Keanir } \\
\text { Yes }\end{array}$ & $\begin{array}{r}\text { 1SSIOn: } \\
40\end{array}$ & & 120 & & \\
\hline No & 10 & 1870 & 1880 & $6 \cdot 0(120 / 2000)$ & $2 \cdot 5(50 / 2000)$ \\
\hline Total & 50 & 1950 & 2000 & & \\
\hline
\end{tabular}

hospital.) To avoid perverse incentives the validity of any proposed outcome indicator must be questioned: Is it known? Is it knowable? At least, is it constant over time or place? As for an outcome indicator based on readmission rates the answer to all these questions is no, its use may seriously mislead and should be avoided.

We thank our colleagues for their suggestions, Tad Matus, Nick Black, and John Gabbay for help and encouragement and Helen Gee and Wendy Weller for their secretarial help.

1 Acheson ED, Barr A. Multiple spells of in-patient treatment in a calendar year. British fournal of Preventive and Social Medicine 1965;19:182-91.

2 Shaw CD. Clinical outcome indicators. Health Trends 1989;21:37-40.

3 Henderson J, Goldacre MJ, Graveney MJ, Simmons H. Use of medical record linkage to Goldacre MJ, Graveney MJ, Simmons H. Use

4 Department of Health and Social Security. Comparing health authorities. Health service indicators 1983-1986. London: DHSS, 1988.

5 Goldacre $M$, Griffin K. Performance indicators - A commentary on the literature. Oxford: Unit of Clinical Epidemiology, University of Oxford, 1983.

6 Health Services Indicator Group. A report on Kömer indicators. London: Department of Health, 1988.

7 Williams DRR. Outcome indicators for diabetic services-what do we have and what do we need? Community Med 1989;11:57-64.

8 Griffiths R. Report of NHS management inquiry. London: Department of Health and Social Security, 1983.

9 National Audit Office. Quality of clinical care in National Health Service hospitals. Report by the comptroller and auditor general. London: HMSO, 1988.

10 Secretaries of State for Health, Wales, Northern Ireland, and Scotland. Working for patients. London: HMSO, 1989. (Cm 555.)

11 Department of Health. Role of district health authorities-analysis of issues. Lepartment of Health.

12 Smith R. Words from the source: an interview with Alain Enthoven. $B M \mathcal{J}$ 1989;298:1166-8.

13 Kind P. Hospital deaths - the missing link: measuring outcome in hospital activity data. York: Centre for Health Economics, University of York, 1988. (Discussion Paper No 44 .

14 Charny M. Death data: do they work? Health Service Journal 1988; December $8: 1450-51$.

15 Woodhouse LW. Called to account: a geriatrician. Lancet 1989;i: 1546.

16 Department of Health. Discharge of patients from hospital. London: DOH, 1989. ( $\mathrm{HC}(89) 5$.)

17 Chambers M, Clarke AE. Measuring readmission rates. BMf 1990;301 1134-6.

18 McPherson K. Variations in hospitalisation rates: why and how to study them In: Ham C, ed. Health care variations. London: King's Fund Institute,

19 Camilleri-Ferrante C, Shaw DA, McLauchlan J. Hospital death rates. BMF 1988;297:426.

20 Jencks SF, Daley J, Draper D, Thomas N, Lenhart G, Walker J. Interpreting hospital mortality data. FAMA 1988;260:3611-6.

21 Moore AT, Roland MO. How much variation in referral rates among general practitioners is due to chance? $B M J$ 1989;298:500-2.

22 Dubois RW, Moxley JH, Draper D, Brooke RH. Hospital inpatient mortality is it a predictor of quality? N Engl $\mathrm{f}$ Med 1987;317:1674-80.

23 Flood AB, Scott WR, Ewy W. Does practice make perfect? Part I. Med Care 1984;22:98-114.

24 Forster DP, Frost CEB, Morris D. Performance indicators in health service management-a clinical analogy. Hospital and Health Services Review 1986; July: $167-70$

25 Barker DJP, Rose G. Epidemiology in medical practice, 2nd ed. London: Churchill Livingstone, 1979:121.

26 Roos LL, Cageorge SM, Austen E, Lohr K. Using computers to identify complications after surgery. Am f Public Health 1985;75:1289-95.

7. Cla A . Are readmissions avoidable? BM7 1990:301:1136-8.

28 Morgan $M$, Mays N. Can hospital use be a measure of need for health care? f Epidemiol Community Health 1987;41:269-74.

(Accepted 4 fuly 1990) 